\title{
Mammary-specific deletion of parathyroid hormone-related protein preserves bone mass during lactation
}

Joshua N. VanHouten, Pamela Dann, Andrew F. Stewart, Christine J. Watson, Michael Pollak, Andrew C. Karaplis, and John J. Wysolmerski

Original citation: J. Clin. Invest. 112:1429-1436 (2003). doi:10.1172/JCI200319504.

Citation for this corrigendum: J. Clin. Invest. 113:492 (2004). doi:10.1172/JCI200419504C1.

A number of errors were included in Table 1. The correct version is as follows:

\section{Table 1}

Histomorphometric analysis of tibias from lactating BLG-Cre/PTHrPlox/- mice and PTHrPlox/- controls

\begin{tabular}{|c|c|c|c|c|c|c|c|c|c|}
\hline & $\begin{array}{c}\mathrm{OcS} / \mathrm{BS} \\
(\%)\end{array}$ & $\begin{array}{l}\text { NOc/BPm } \\
\text { (no./mm) }\end{array}$ & $\begin{array}{c}\text { ObS/BS } \\
(\%)\end{array}$ & $\begin{array}{c}\mathrm{NOb} / \mathrm{BPm} \\
\text { (no./mm) }\end{array}$ & $\begin{array}{c}\text { BFR/TV } \\
(\% / y r)\end{array}$ & $\begin{array}{c}\mathrm{BV} / \mathrm{TV} \\
(\%)\end{array}$ & $\begin{array}{l}\text { TbTh } \\
(\mu \mathrm{m})\end{array}$ & $\begin{array}{l}\text { TbSp } \\
(\mu \mathrm{m})\end{array}$ & $\begin{array}{c}\mathrm{TbN} \\
\text { (no./mm) }\end{array}$ \\
\hline$P|x|--$ & $7.0 \pm 1.0$ & $2.3 \pm 0.3$ & $18.2 \pm 2.3$ & $21.8 \pm 3.4$ & $372.7 \pm 36.2$ & $6.1 \pm 0.5$ & $25.3 \pm 2.1$ & $402.2 \pm 48.4$ & $2.46 \pm 0.27$ \\
\hline Cre/PTHrPlox/- & $3.0 \pm 0.5^{\mathrm{A}}$ & $1.0 \pm 0.1^{\mathrm{A}}$ & $18.7 \pm 1.9$ & $26.0 \pm 3.0$ & $219.5 \pm 30.0^{\mathrm{B}}$ & $6.8 \pm 1.2$ & $21.9 \pm 2.1$ & $379.9 \pm 96.1$ & $3.28 \pm 0.62$ \\
\hline
\end{tabular}

A $P<0.005 ; B P<0.05$. Static and dynamic histomorphometric analysis of tibias from day 12 lactating BLG-Cre $/ P T H r P l o x /-$ mice $(n=7$, static; $n=4$, dynamic and PTHrPlox/- littermate controls $(n=4$, static and dynamic). Values are shown as mean \pm standard error. OcS/BS $(P<0.005)$, NOc/BPm $(P<0.005)$, and BFR/TV $(P<0.05)$ were significantly lower in the BLG-Cre/PTHrPlox/- mice than in controls. OcS/BS, osteoclast surface as a percentage of bone surface; $\mathrm{NOc/BPm}$, number of osteoclasts per mm bone perimeter; ObS/BS, osteoblast surface as a percentage of bone surface; NOb/BPm, number of osteoblasts per mm bone perimeter; BFR/TV, bone formation rate as a function of tissue volume; BV/TV, trabecular bone volume as a function of tissue volume; TbTh, trabecular thickness; TbSp, trabecular separation; TbN, trabecular number. 